\title{
PERFIL DE IDOSAS PRATICANTES DE EXERCÍCIO FÍSICO ONLINE DURANTE A PANDEMIA
}

Priscilla Cardoso da Silva'; PPGCMH/UFRGS; priscilla.cardoso@ufrgs.br; Débora Pastoriza Sant' Helena1; PPGCMH/UFRGS; deborapsh24@gmail.com; Luciane Job Junqueira dos Santos²; UFRGS; luciane.job.74@gmail.com; Ruane Cardoso Nolasco²; UFRGS; ruanenolasco@gmail.com; Andréa Gonçalves Kruger; PPGCMH/UFRGS; andreakgoncalves@gmail.com

\section{RESUM0}

Introdução: A Universidade Aberta para Pessoas Idosas (UNAPI/UFRGS) criou a UNAPI ATIVA, um programa de aconselhamento semanal de exercícios físicos, com aulas de 60 minutos, por meio de plataforma online (MConf) e aplicativo de mensagens instantânea(Whatsapp) para reforçar aprendizagem e a interação dos alunos idosos com a equipe. $\mathrm{O}$ programa visa através das aulas a promoção de saúde, bem estar, independência, qualidade de vida, evitando o comportamento sedentário dos idosos ocasionado pela pandemia do COVID-19. Objetivo: Identificar o perfil dos participantes de um programa de exercícios físicos online durante a pandemia. Método: Estudo cross-sectional, através de questionário sociodemográfico e de saúde com análise descritiva (SPSS21.0) (Comitê Ética UFRGS:071479/2020). Resultados: Todas são mulheres ( $\mathrm{n}=17)$, $58,8 \%(\mathrm{n}=10)$ tinham entre 60 a 69 anos e $41,1 \%(\mathrm{n}=7) 70$ a 81 anos. Destas, $47,1 \%(\mathrm{n}=8)$ são casadas, $29,4 \%(\mathrm{n}=5)$ divorciadas, 52,9\%(n=9) moram sozinhas ou com filhos, $47,1 \%(\mathrm{n}=8)$ com cônjuge. Os problemas de saúde mais relatados foram: $\operatorname{artrose}(47,1 \%)$, artrite(17,6\%), osteoporose(17,6\%); $41 \%$ sentem dor no joelho, $23,5 \%$ na mão/punho, $23,5 \%$ não sentem dor; e $88,2 \%(n=15)$ não caíram nos últimos 6 meses. Em relação a medicação, 82,4\%(n=14) ingerem medicamentos e 17,6\% ( $\mathrm{n}=3$ ) não usam. Na prática de exercício físico antes da pandemia, 13 idosas $(76,5 \%)$ relataram praticar (47,2\% caminhada e 29,5\% musculação) e 4 não praticavam (23,5\%). Os principais objetivos das alunas com as aulas online foram a melhora do estado físico e mental. Conclusão: Identificamos que as mulheres possuem maior preocupação em se manterem ativas e o programa foi relevante para comunidade idosa neste momento de pandemia.

Palavras-chave: Exercício Físico; COVID-19; Idoso.

Agradecimento: O apoio a Coordenação de Aperfeiçoamento de Pessoal de Nível Superior- Brasil (CAPES) ${ }^{1}$ - Código de Financiamento 001, e ao Programa de Bolsa de Extensão Universitária (PROREXT/UFRGS) ${ }^{2}$. 